\title{
Language Model and Grammatical Constraints on Code-Switching in The Case of Bahasa Indonesia-Chinese
}

\author{
Wa Ode Siti Hardianti Halidun* Bai Chen \\ School of Foreign Languages and Literature, Tianjin University, PO box 300350, 135 Yaguan Road, China
}

\begin{abstract}
Code-switching refers to the process of mixing different language features within a single passage that may cause a contrasting effect. This study aims to reveal the grammatical constraints on intra-sentential code-switching in the case of Bahasa Indonesia-Chinese by collecting the data of code-switching of 14 Indonesian students in Tianjin. The result finds that The language model in the case of Bahasa Indonesia-Chinese code-switching shows that Bahasa Indonesia is the dominant language for most cases. However, the switched with the same structure with Chinese, and have the same frequent occurrence of morpheme cannot be assigned into the ML and EL, only switched cases with system morpheme, and Bahasa Indonesia is the frequent morphemes can be accounted into ML or EL. The cases of switched sentences between the aspect of time and verb answer the assumption that a switch may occur even at the surface structure of the participant languages that do not map onto each other. Moreover, the free morpheme constraint analysis using the minimalist program, the bound morphemes of Bahasa Indonesia that denote determiner and possessive, can be cut from its position to project the maximal projection in VP, and still, retain a free morpheme. This finding does not violate the free morpheme constraint theory. However, the passive form switched shows that a switch occurs between bound morpheme and the lexical. The bound morpheme cannot be cut and retain a free morpheme. The switched sentences that are analyzed by the minimalist program, moreover, the result finds that when the bound morpheme cut from its position to retain a free morpheme, it falls under the lower constituent under PP.
\end{abstract}

Keywords: Code-switching, the grammatical constraints, language model on code switching, bahasa IndonesiaChinese, the matrix language frame model, the minimalist program 1

DOI: $10.7176 / J L L L / 66-05$

Publication date:March $31^{\text {st }} 2020$

\section{Introduction}

In a multilingual community, people carry a conversation using more than one language is prevalent. The speakers often change one language into another language in a single conversation, back and forth. It occurs consciously or subconsciously and mostly happened among the fluent bilinguals. It is a coincidence. Still, the linguists have been paying attention to study this phenomenon since decades ago. This phenomenon is called code-switching or codemixing.

Bokamba (1989) defines both concepts as the following: code-switching is the mixing of words, phrases, and sentences from two distinct grammatical systems and subsystems across sentence boundaries within the same speech event. Code-mixing is the embedding of various linguistic units such as affixes (bound morphemes), words (unbound morphemes), phrases, and clauses from a cooperative activity where the participants in order to infer what intended, must reconcile what they hear with what they understand. In the recent study, Muysken (2000:1) refers to code-switching as "the rapid succession of several languages in a single speech event," and code-mixing refers to "all cases where lexical items and grammatical features from two languages appear in one sentence." However, this study will mark the term code-switching rather than code-mixing. Code-switching refers to the process of mixing different language features within a single passage that may cause a contrasting effect. In that concept, code-mixing views as the product of switching languages.

Code-switching became a developed and well-established field of research by the 1970s after it emerged firstly in the 1950s and 1960. At first, code-switching was seen as the indication of a language disability of some kind or perhaps was indicative of a lazy speech. The scholars have proposed various definitions of code-switching, but it ends at the same point. The definition of code-switching has been suggested by MacSwan in Mouton, eds, (2016: 1) that "code-switching is a speech style in which fluent bilingual speakers switch languages between or within sentences." MacSwan argues that code-switching is a speech style that commonly occurs among fluent bilinguals. He took an example of English-Spanish case This morning mi hermano y yo fuimos a comprar some milk (This morning my brother and I went to buy some milk). The speaker started with English then switched it to Spanish. The situation of the speaker described as the unconscious condition where the speaker did not know they switched the language. Code-switching researchers have accepted this study. Penelope Gardner Chloros (Félire Óengusso, 2017), for example, points to the fact that speakers who are in some sense vaguely aware of their own code-switching practices often show surprise or embarrassment about the extent of their mixing when they are confronted with recordings of their speech.

Moreover, Gardner-Chloros (2009) asserts the meaning of code-switching as the combination of two and 
more linguistic varieties in countless bilingual societies and communities. The speakers practically use different languages and dialects in the same conversation. However, the statement of code-switching is not only lean on the fluent bilingual speakers. Switching may be occurred by the speakers who can speak more than one language, but not only the fluent bilingual speakers. It gives them space to mix different language elements in the same conversation. This case relates to Muysken (1995) that claims code-switching as the alternative use by the speakers of two or more languages.

However, some researchers suggest that code-switching is not a phenomenon that happens among bilingual speakers; it also takes place among the monolingual speakers who may mix various dialects and language style. Likewise, Gumperz (1982:59) denotes the term as "the juxtaposition within the same speech exchange of passages of speech belonging to two different grammatical systems or subsystems." It means code-switching does not only stand as the speech act or behavior of the speakers who were mixing the variation of language features but also as the contrasting effect of mixing different grammatical systems or sub-systems. Romaine (1989) relates the phenomenon of code-switching, as Gumperz (1982) argues that in code switched discourse, the items in question form part of the same speech act. They are tied together prosodically as well as by semantic and syntactic relations equivalent to those that join passage in a single speech act.

In regards to the grammatical study of code-switching, many linguistic researchers have taken an effort to understand the patterns by trying to reveal universal constraints of code-switching using different languages and methods, such as English-Spain, Swedish-English, Moroccan Arabic-French, Indonesian-English, ChineseEnglish, but not Bahasa Indonesia-Chinese language. However, the result shows different patterns and constraints on each different language switching case. It means every new case study of language on code-switching will bring the novelty on code-switching pattern research.

The motivation to propose grammatical studies of code-switching was departed from the point of which bilingual code-switching is highly structured, and rule-governed (MacSwan in Mouton, 2016). It means when the languages are in contact, there is a possibility to have a syntactical restriction. This principle relates to the discussion of what constitutes a linguistic system, cites of an example of Spanish-English code-switching, and Labov in Romaine (1995:115) notes that it must be described as the irregular mixture of two distinct systems.

However, the problem is because the theories were claimed to be universally applied for all languages. Many scholars have tried to re-examine the theories, such as Berk-seligson (1986), who studied grammatical constraints using the case of Spanish-Hebrew bilinguals. It is assumed by both languages are highly divergent in the case of syntactic similarity.

In grammatical constraints analysis on code-switching of Morrocoan Arabic-French that was investigated by Redouane (2005), switching such as between verb and object and between noun and adjective that occurred despite the syntactic difference between the two languages result in ungrammatical sentences in either Arabic or French. The data also revealed that the size of the constituent constraint had been violated.

Furthermore, Van Gaas (2002) comes to re-examine the validity of Poplack's and Belazi, et. al's grammatical constraints theory by analyzing the case of Afrikaan-English code-switching using the minimalist program of Chomsky. The study argues that Poplack's Free Morpheme Constraint and Belazi et al's Functional HeadConstraint, against the English-Afrikaans code-switching data collected. The study also suggested possible explanations for aspects of the data unaccounted for by Poplack (1981) and Belazi et al (1994). The findings indicate that Poplack's Free Morpheme Constraint is supported by the code-switching data. However, it is suggested that Belazi et al's Functional Head Constraint be modified in order to account for aspects of the data that do not correspond to the empirical predictions of this constraint, specifically the switching of conjunctions (van Gass, 2002: 107).

Meanwhile, Wang and Liu (2013) tried to reveal the pattern of code-switching both syntactically and cognitively by using the structuralist approach of Word Grammar by Hudson (2010). The study assumes that Word Grammar is an effective theory to analyze both structurally and cognitively, because it displays relatively clearly the research approach of finding the human cognitive mechanism by analyzing the language structure. The study found that code-switching affects language syntactic structure in terms of the dependency distance and the dependency direction. Cognitively, by comparing the dependency distance, a measure of memory load in Word Grammar, it was mainly found that mixed dependencies present longer distances than monolingual ones. Moreover,primary grammatical functions (subject, object, attribute, and adverbial) play essential roles in syntactic variations. However, the study also suspects that the variation word order on code-switching of Chinese-English cannot be claimed because code-switching is typologically different from the monolingual ones (Wang and Liu, 2013:71).

Thus, many varieties of language cases and methods have been proposed to understand regular patterns of code-switching, but the restrictions of each language case are divergent. It means that the system of language is more complicated when two different linguistic features are involved. However, every new language case contributes to the analysis of code-switching in terms of what rules restrict two languages when they are in contact to avoid building another particular pattern. 


\section{Method}

The research aims to uncover grammatical constraints on code-switching in the case of Bahasa Indonesia-Chinese language, and what rules restrict it. The data will be using qualitative analysis to generate and examine the data by applying Poplack's grammatical constraints theory (1981). The analysis is also elaborated to find language model of Bahasa Indonesia-Chinese code-switching by using matrix language frame model of Myers-Scotton (1993) by examining the Matrix Language (ML hereafter) and Embedded Language (EL hereafter). Finally, the restriction rules on code-switching in Bahasa Indonesia-Chinese is analyzed by applying the minimalist program of Chomsky (1995).

\subsection{Participants}

This study investigated 30 Indonesian students in Tianjin who can able to speak Chinese, but only 14 of them can be counted in data analysis. All investigated participants who did not switch the languages removed from the data.

\subsection{Setting}

The collecting data of the participants designed in a natural setting by recording their conversation and by taking notes when the switch occurred out of the recording time. The conversation was taken without noticing the participants so that the data will be natural without any intervention. It was also done to broaden the data on codeswitching in the case of Bahasa Indonesia-Chinese.

\section{Results and Analysis}

\subsection{Language model on code-switching of Bahasa Indonesia-Chinese}

3.1.1. ML negation + EL verb

In this case EL verb is inserted into another language structure during code switched process.

(1) Aku bilang kamu jangan da che, pasti macet

(I say you do not need to call taxi, it will be traffic jam).

From above example, Bahasa Indonesia dominates the language of code switching. It also shows that the morphemes in Bahasa Indonesia appears six times while Chinese has two. Moreover, the structure of the sentence also follows the structure of Bahasa Indonesia and Chinese, which negation Jangan comes before verb da che. Even though the structure of the sentence can be assigned as EL structure, but the frequent use of morphemes are under Bahasa Indonesia morphemes, so it can be summarized that the language model of the case is based on ML, Bahasa Indonesia. The code switched sentence of the case also comes to support the grammatical constraints theory of Poplack (1981), the equivalence constraint. The theory states that code switching may occur at point when the surface structure of code switching languages meet in the same order.

In Myers Scotton (1993), it is important to distinguish content morpheme and system morpheme on code switching case in order to understand the constraints. It bases from the principle that the patterns of occurrence of morphemes in bilingual code switched speech are constrained by the status of morphemes. In (1) the switched occurs under content morpheme i.e. verb phrase to call taxi. The verb call is thematic role assigner and taxi is the receiver, and to call taxi is categorized under EL island rather than EL constituent since it does not occur as a word but a phrase. However, in this case $d a$ che cannot be $d a$ taxi because the da triggers the noun che to be activated and keep the ML word from being activated, so EL island is created under the verb phrase.

3.1.2. ML Verb + EL Noun

(2) Aku sudah print piao untungnya

(Luckily, I have printed the ticket)

In this case EL noun is inserted into ML constituent and the sentence structure is under ML control. The adverb untungnya follows the structure of Bahasa Indonesia rather than Chinese, which it is put after the noun piao. In Chinese, the position luckily should be put after subject or before subject to remain grammaticality.

Based on the blocking hypotheses in Myers Scotton (1993), the ML blocks any EL content morphemes if its counterpart is a system morpheme in the ML. The word untungnya assigns the insertion of determiner inflection $-n y a$, and it carries the feature +quantification that the order of the system morpheme follow the ML order (Myers Scotton, 1993). This status blocks any EL content morpheme to be activated, so the sentence is rather occurred in ML structure than EL structure. In addition, the first morphemes occurred in ML structure Aku sudah print piao, which it makes the adverb untungnya comes late, so it forces the word to be assigned in ML structure.

(3) Aku naik ditie, meiyou piao lagi

(I took subway, again the ticket sold out)

However, the case demonstrates that the ML hypotheses seems not work. Bahasa Indonesia has three morphemes, and Chinese has five morphemes. Meanwhile the sentence is under the structure of Bahasa Indonesia, which the adjective lagi occurs after the noun piao. The adjective lagi, however, cannot be placed after the noun piao, or it will cause ungrammaticality in Chinese structure. Moreover, the content morphemes of the switched sentence falls under Chinese morphemes meiyou piao, and the phrase is a maximal projection that meiyou piao is under the 
constituent which is projected to the highest level from the lexicon. While in ML principles, morpheme order is controlled by ML. This case shows that ML and EL cannot be decided by counting the frequent use of morphemes in one segment.

\subsubsection{Negation + EL Noun}

This case shows EL noun in ML, and it falls under EL constituent. The noun, however, is under ML control.

(4) Kapan aku bilang kamu ga ada qiantu?

(when did I say you don't have a future?)

In (4), Bahasa Indonesia is the dominant language. The distribution of the morphemes in Bahasa Indonesia is more than Chinese. Bahasa Indonesia has six morphemes, and Chinese has two. The structure of the sentence falls under the both languages, which the EL noun qiantu comes before the verb phrase ga ada. Thus, this example satisfies the hypotheses of ML, that the surface structure of the ML+ EL constituents based on the ML grammar (Myers Scotton, 1993).

Unlike the previous examples, this case demonstrates that the EL morpheme is activated when the surface structure of both languages map each other, so the occurrence of the EL morphemes do not affect the structure of both languages from being ungrammaticality. This example does support the grammatical constraints theory of Poplack (1981), that code-switching occurs at any point when the surface structure of respective language maps each other.

3.1.4. EL Content + ML System Morpheme

(5) Ga bagus-bagus amat juga qiantuku

(I also don't have a good future)

(6) Yang kalah ada chengfanya

(who fails will get punishment)

(7) Aku lupa nomor gong jiao chenya

(I forgot the number of the bus)

(8) soalnya di kamar kita shuanya tiga kali

(because our room must be tapped three times)

These cases are described to account for the distinction of content morpheme and system morpheme in ML hypotheses. In (5) code switching occurs in the Bahasa Indonesia constituent, the noun phrase qiantuku. The inflection $-k u$ was attached to express the possession in this case. The structure of the system morpheme $-k u$ follows the structure of Bahasa Indonesia, which should follow the noun qiantu. It was explained in chapter two that Bahasa Indonesia is a head-final language on its noun phrase, in which the head of the word comes after another word. Moreover, Bahasa Indonesia has five morphemes that include one system morpheme, and the Chinese has two morphemes. Therefore, Bahasa Indonesia is the dominant language in this case. However, the restriction falls under the noun phrase structure qiantuku. This assumes that the inflection $-k u$ is activated in EL content morpheme but it comes under ML grammar control because the EL content morpheme qiantu carries +quantification that denotes possessive $-k u$. Thus, this case agrees with system morpheme hypotheses that all system morphemes in a code switched sentence will come from the ML (Myers Scotton, 1993).

This case also appears in (6), (7) and (8), yang kalah ada chengfanya in (6) the content morpheme chengfa precedes the system morpheme -nya. The inflection -nya, in this case, refers to a particular punishment, that the person who loses will surely get the punishment. The morphemes in Bahasa Indonesia are four, with two Chinese morphemes. The structure of the sentence is under Bahasa Indonesia, not Chinese, this can be seen from the system morpheme order that allows the order of Bahasa Indonesia, which - nya comes after the noun 惩罚. In this case nya is a determiner, and the determiner in Chinese should precede the noun to remain grammaticality in its noun phrase structure.

Similar to (6), the example in (7) Aku lupa nomor gong jiao chenya, the system morpheme -nya acts as the determiner of the noun phrase 公交车gong jiao che, and the inflection -nya carries the feature +quantification. The structure of the system morpheme follows Bahasa Indonesia grammar, which the inflection -nya that denotes a determiner should come after the noun. The noun phrase gong jiao che has feature +thematic roles receiver, which the noun phrase receives the argument from the verb lupa. The noun phrase is categorised as the content morpheme that the structure is under Bahasa Indonesia structure. Therefore, the sentence takes Bahasa Indonesia as the ML.

In (8), the system morpheme of ML can be attached in EL verb shuanya on code-switching of Bahasa Indonesia-Chinese case. In this case, the morphemes are more in Bahasa Indonesia with seven morphemes that include one system morpheme, and the Chinese has one. The structure of the sentence is also based on Bahasa Indonesia grammar, which the inflection of the determiner - nya follows the structure of Bahasa Indonesia. The inflection -nya is carrying the feature +quantification, and is under Bahasa Indonesia structure. The verb shua, moreover, has feature thematic role assigner that denotes the content morpheme of the sentence.

Code-switched cases in (5), (6), (7) and (8) seem to satisfy the hypotheses of system morpheme order, that all system morphemes in a code-switched sentence will come from the ML (Myers Scotton, 1993). The constraints on the system morphemes are rather following the ML grammar because the ML blocks any EL content 
morphemes if its counterpart is a system morpheme in the ML. (Myers Scotton, 1993). Therefore, it predicts that qiantuku, chengfanya, gong jiao chenya, and shuanya cannot be switched as my future, the punishment, the bus, and the tapping because the inflection are carrying the system morpheme in ML structure.

(9) Yang kalah dichengfa

(who fails will get the punishment)

(10) oh, kartunya harus dishua gitu ya

(oh, the card should be tapped?)

Nevertheless, in (9) and (10) the constraints cannot be accounted by separating the content morpheme and the system morpheme. The both example in (9) dichengfa and in (10) dishua, the passive form - di are activated in the both code switched sentence in Bahasa Indonesia without carrying the feature +quantification, while the content morpheme chengfa and shua are activated in Chinese with carrying the feature +thematic role assigner. However, the frequent use of the morphemes are in Bahasa Indonesia, and the structure of the morphemes are based on Bahasa Indonesia grammar, which the passive form - di precedes the verb. Thus, the language model of the code switched sentence is under Bahasa Indonesia control.

3.1.5. ML Progressive + EL Verb

This case presents that EL verb inserted into ML under EL constituent, and code switched occurs between ML auxiliary and EL verb. The structure of the code switched sentence is under Bahasa Indonesia, and the Chinese structure and the distribution of the morphemes are the same, which Bahasa Indonesia and Chinese have two morphemes, respectively.

(11) Dia masih shixi

(he is still an intern)

In the case above, the progressive masih precedes the noun phrase shixi. The structure does not violate the structure of Bahasa Indonesia and Chinese, in which the noun phrase should be preceded by the progressive in the respective languages. In this case, ML and EL cannot be determined by counting the occurrence of the morphemes, but by looking the morphemes under which constituent, it demonstrates that there are two different constituents under Bahasa Indonesia morphemes, i.e. Dia and Masih. Meanwhile, shixi is under one constituent, which accounts for the verb phrase. Thus, the dominant language of the case is Bahasa Indonesia.

This case also agrees with the morpheme order hypotheses in Myers Scotton (1993), that the order of morphemes in a code switched sentence must follow the ML order of morphemes. Moreover, the code switched sentence occurs when two languages that take part in code switched sentences follow the surface structure of both the languages, respectively (Poplack, 1981).

3.1.6. ML intensifier + EL adjective

(12) Dapurku lebih gaoji

(my kitchen is more advance)

(13) Karena dalam bahasa mandarin grammarnya sangat fuza

(because Chinese has a complicated grammar)

Code-switching, in the case of Bahasa Indonesia-Chinese, allows the switching between ML intensifier + EL adjective. In (12) and (13) sentences, Bahasa Indonesia is the dominant language that is measured by the frequent use of the morphemes, which the morphemes that are under Bahasa Indonesia occur two times in different constituent in (12), and Chinese has two morphemes too, but they are under the same constituent. Moreover, the case in (12) follows the surface structure of both the languages, respectively, in which an intensifier comes first before the adjective.

Besides, the example in (13) shows the same, which the intensifier sangat precedes the adjective fuza. The dominant language of the case is Bahasa Indonesia, which it gets six morphemes with five different constituents that are complement, preposition, noun phrase, pronoun, and adjective phrase, while Chinese has two morphemes under the adjective phrase. Also, the case shows that the code switched sentence occurs when the surface structure of the respective languages that are taking part in code-switching direct at the same order. Therefore, case (12) and (13) also support Poplack's theory of equivalence constraint (1981), and the morpheme order hypotheses in Myers Scotton (1993).

3.1.7. ML Noun + EL Verb

(14) Tapi aku faxian ya, dia itu punya cewek

(But I found, he got a girlfriend already)

This case demonstrates that in the case of Bahasa Indonesia-Chinese code-switching, the switched can occur in EL verb in ML. In (14), Bahasa Indonesia is the ML because it has seven morphemes, and the Chinese has two morphemes under one constituent. The verb faxian is carrying the feature +thematic role assigner because it assigns the complement phrase dia itu punya cewek and the pronoun aku. However, the role of the verb, in this case, does not affect the structure of Bahasa Indonesia. The structure of the switched sentence follows both Bahasa Indonesia and Chinese structure, which a pronoun should come before the verb. This case also shows the equivalence constraint theory of Poplack's (1981) and the morpheme order hypotheses of Myers Scotton (1993) work to account 
for the data.

\subsection{Grammatical Constraints of Bahasa Indonesia-Chinese Code Switching}

3.2.1. Equivalence constraint

(1) Besok nuanqi sudah nyala

(Tomorrow the heater will be on)

(2) mereka tiap hari manke

(They have a full class everyday)

(3) Dia itu hen yan ge

(he is so strict)

(4) Karena dalam bahasa mandarin grammarnya sangat fuza

(because Chinese has a complicated grammar)

(5) wo yao tulis tentang yuyin

(I want to write about Phonetics)

(6) aku naik ditie, meiyou piao lagi

(I took subway, again the ticket had sold out)

These cases present the equivalence constraint in the case of Bahasa Indonesia-Chinese code-switching. In (1), the switch occurs between adjective Besok noun phrase nuanqi under DP position. The switched sentence remains grammaticality under the structure of Bahasa Indonesia-Chinese, which adjective besok should follow the noun phrase nuanqi, or the noun phrase precedes the adjective. The switched sentence agrees with the equivalence constraint theory by Poplack (1981), which a switch may occur at any point when the surface structure of participant languages order in the same way. However, the sentence (1) is impossible to switch between the aspect of time sudah/le and the verb nyala/kai, because it will cause ungrammaticality. Consider the following derivations.
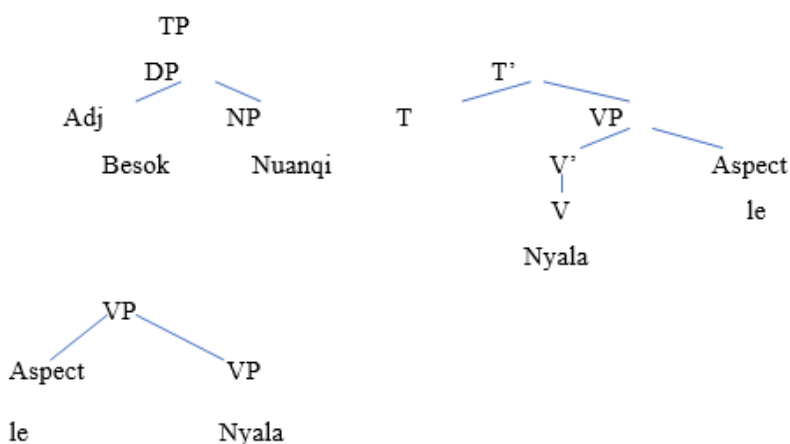

Then, why is it not possible to realize le as a past time in the switch case? It assumes that because in Bahasa Indonesia structure, aspect of time le merges with $\mathrm{V}$ kai to form VP projection, while in Chinese, $\mathrm{V}$ should merge the aspect le to form a maximal projection VP. In Chinese, in order to be grammatical, the phrase should be placed as kai le but not *le kai. According to MacSwan in Mouton, eds (2000: 46), code-switching at PF generates unpronounceable elements because phonological systems cannot be mixed. It means that if the two PF components are mixed in the same way as the two lexicons for mixing in the syntactic component, the ordering of rules will not be preserved. Moreover, if $l e$ realizes at $\mathrm{PF}$ as the specifier of VP, it may violate the aspect structure in Chinese.

The assumption is supported by the switching case in (6), which the aspect lagi tends to realize under the structure of Bahasa Indonesia. This suggests that because lagi in Bahasa Indonesia has two meanings. When lagi is placed before meiyou piao in (6) the meaning will be changed as hai rather than you. In addition, moving the aspect of hai/you after VP position will cause an ill form in Chinese structure, i.e. *meiyou piao you.

In the previous part, the language model in the case of Bahasa Indonesia-Chinese code-switching tends to follow Bahasa Indonesia rules rather than Chinese. Nevertheless, some cases cannot be accounted for ML hypotheses, that the morpheme order follows the ML. ML can be determined by separating content morpheme and system morpheme. The example in (5) wo yao tulis tentang yuyin shows that the sentence cannot be determined as ML or EL, since the dominant language cannot be determined. However, the case supports the theory of Poplack's (1981) equivalence constraint, which the structure both Bahasa Indonesia and Chinese order in the same way.

(5) [TP[PRN wo[VP yao tulis[PP[Ptentang[NP yuyin]]

The derivation above demonstrates that the position of the switched sentence will not violate both the languages structure, unlike the construction code-switching in (1) and (6), between aspect and verb. In Bahasa Indonesia and Chinese, the co-verb yao precedes the verb tulis. This derivation also shows that the code-switching may occur at any position without violating the structure of participant languages. For example, the switching can occur between 
verb tulis and preposition tentang, such in Aku mau xie guanyu Fonetik.

In the case of Bahasa Indonesia-Chinese code-switching, the switch can occur between intensifier and the adjective, such in (4) Karena dalam bahasa mandarin grammarnya sangat fuza. Both in Bahasa Indonesia and Chinese, intensifier sangat should precede the adjective fuza. Moreover, in (3) Dia itu hen yan ge the switch occurs between determiner phrase position dia itu and adjective phrase position hen yan ge. Because both (4) and (3) order in the same way, the switch may occur at any position even in internal structure without forming ungrammaticality for both the languages, Bahasa Indonesia and Chinese. The assumption is the same as in (2) mereka tiap hari manke, when determiner position mereka tiap hari in Bahasa Indonesia and verb phrase in Chinese manke are in a switch, the structure of both the languages remain grammatical. Thus, it can be summarized that switching in (4), (3), and (2) can be accounted for in the equivalence constraints theory that the switching may occur when the order of the participant languages map onto each other.

4.3.2. The Free Morpheme Constraints

In Poplack (1981), one of the constraints on code-switching is predicted that a switch may not occur between a bound morpheme and a lexical form unless the lexical form has been phonologically integrated into the language of the morpheme. These cases that are presented below demonstrate that code-switching in the case of Bahasa Indonesia-Chinese allows the switch between a bound morpheme and a lexical form. It means the free morpheme constraint theory of Poplack (1981) cannot be in line with code-switching in the case of Bahasa Indonesia.

(7) Ga bagus-bagus amat juga qiantuku

(I also don't have a good future)

(8) Yang kalah ada chengfanya

(who fails will get the punishment)

(9) Aku lupa nomor gong jiao chenya

(I forgot the number of the bus)

(10) soalnya di kamar kita shuanya tiga kali

(because our room must be tapped three times)

(11) Yang kalah dichengfa

(who fails will get the punsihment)

(12) oh, kartunya harus dishua gitu ya

(oh, the card must be tapped?)

The analysis of language model on code switching in Bahasa Indonesia-Chinese, the model follows the structure of Bahasa Indonesia, in which the language is the dominant language. This assumption relates to the morpheme order, and the system order hypotheses that stated the morpheme order and the system order allow the dominant language rules to be applied on code-switching (Myers-Scotton, 1993).

In cases (7), (8), (9), and (10), the bound morphemes function as possessive pronoun and determiner. According to the system morpheme in MLF model (Myers-Scotton, 1993), the system morpheme carries the feature +quantification (determiner, possessive, progressive, quantifier, and etc). The system morpheme, however, should follow the ML model on code-switching. The cases above seem to satisfy the ML hypotheses, but it does not seem to satisfy the free morpheme constraint of Poplack (1981) because the system morpheme was attached to the lexical. Nevertheless, this study suggests that the cases in (7), (8), (9) and (10) do not violate the free morpheme because the bound morpheme can be cut under the constituent to retain a free morpheme under different constituent. Consider the derivation below under the noun phrase qiantuku.

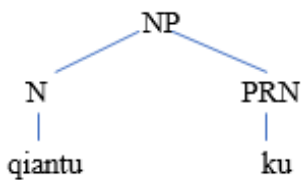

Even in Bahasa Indonesia it will remain grammatical when the bound morpheme $-k u$ cuts and moves to PRN constituent, masa depan aku. It is the same as in (8), (9), and (10), the bound morpheme -Nya were inflected to denote determiner on the sentences. The bound morpheme -Nya can be cut from the lexical and retain a free morpheme. In MacSwan in Mouton, eds (2016: 188) credits to Poplack (1981) states that a switch may occur at any point in the discourse at which it is possible to make a surface constituent cut and still retain a free morpheme.

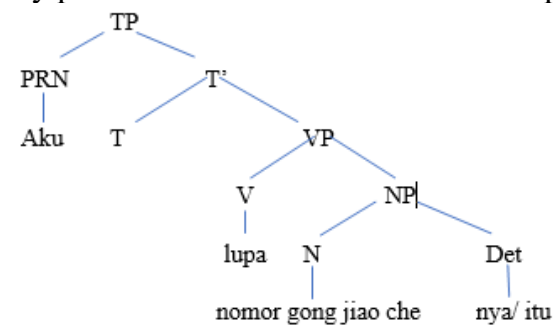


The bound morpheme -Nya can be cut from its constituent and retain grammaticality by changing the pronunciation $-N y a$ to be $i t u$ without violating the structure and the meaning. By changing the pronunciation of Nya to be itu, the bound morpheme can be cut, and it can occupy the position under the determiner. Similar to (10) soalnya di kamar kita shuanya tiga kali, the bound morpheme -Nya can still be cut and retain a free morpheme by changing to itu to be able standing under the determiner position.

In (8) Yang kalah ada chengfanya, -nya can still be cut and retain grammaticality as in (9) and (10). However, the bound morpheme -nya seems the only bound morpheme that realizes at PF. chengfa roles as NP in this case. In Bahasa Indonesia, chengfa is coming from the word verb hukum/chengfa. In order to change the category of the verb, the inflection -an that denotes a noun should be attached on the root, so it will be hukum-an/chengfa. In fact, it is impossible for -an to be realized at PF when it is in a switch, such as *chengfaan, to be understood as NP.

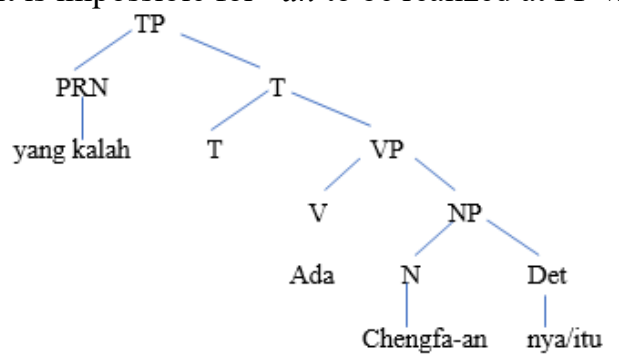

The derivation above shows that the category that can be cut is only the bound morpheme -nya, while -an cannot be cut and retain a free morpheme because it must be under the $\mathrm{N}$ position. Based on the derivation, -an does not have a role in projecting the NP, chengfanya as the bound morpheme -nya. In fact, the NP is the projection of N chengfa and the determiner - nya/itu.

An operation spell out applies to strip away from the derivation those elements relevant only to PF (MacSwan in Mouton, eds, 2016). It bases from the checking element at the logical form, and it must be checked again at phonetic form. Chinese does not carry inflection - an to form an NP in verb chengfa, it is only from the derivation that chengfa occupies NP in the switched sentence. It may be assumed that the inflection -an is unpronounceable element in the switch in the case of Bahasa Indonesia-Chinese. Thus, this case demonstrates the free morpheme constraint of Poplack (1981) can account for the data, in which a switch may not occur between a bound morpheme and a lexical form unless the lexical form has been phonologically integrated into the language of the morpheme. However, the cases in (11) and (12) seem to opposite the free morpheme constraint theory. The passive form in (11) cannot be cut to form the lexical chengfa, or it will function differently in derivation. Consider the following derivations under the verb phrase.
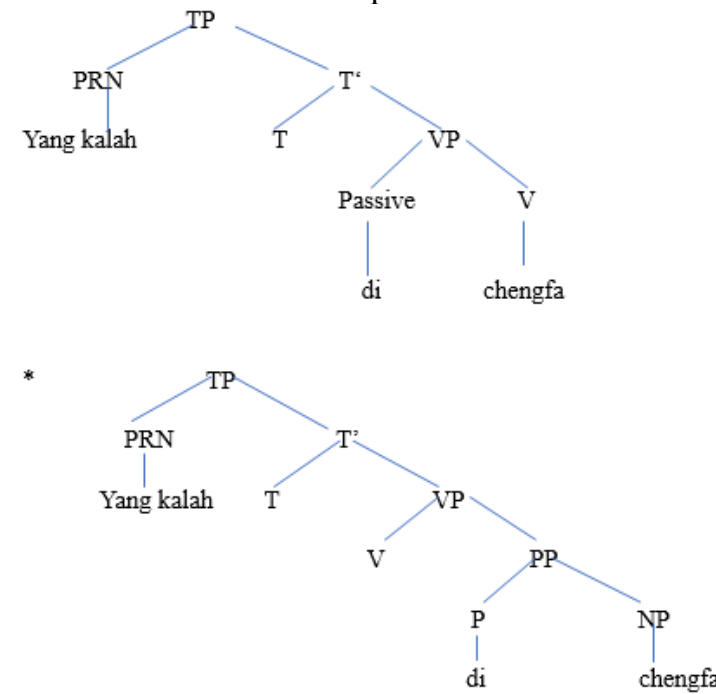

The VP is a projection of the passive form - di merges with verb chengfa, so it is impossible to cut - di from the position. If the passive - di was cut, the category should be moved lower under PP projection, and it means chengfa must be moved under NP position. This movement will clash at logical form during checking elements that the word dichengfa carries semantic feature \pm verb or \pm noun. Therefore, in order to be realized at PF, the passive form - di should attach to its lexicon. The construction above is also applied in (12), that dishua cannot be cut from its position to retain a free morpheme, or it will violate the meaning of the expression. Thus, in the cases, come to demonstrate that the free morpheme constraint cannot be accounted for in case of passive form in Bahasa Indonesia-Chinese code-switching. 


\section{Conclusion}

Code-switching phenomenon in Bahasa Indonesia-Chinese found among Indonesian learners of Chinese in China. This study believes that every pattern that was built by the speakers of switching language involves rules that governed. They are tied together by syntactic and semantic relationships. Therefore, this study will be focusing on the constraints on code-switching rather than the patterns.

This study investigated 30 Indonesian students in Tianjin who are able to speak Chinese, but only 14 of them can be counted for data analysis. All investigated participants who did not switch the languages are removed from the data. During collecting the data, the setting was set in a natural setting conversation, which the participants did not know they were being investigated. There was no restriction on the topic of conversation to broaden the data of analysis. Moreover, the data were analyzed by applying Poplack's (1981) theory of grammatical constraints, language matrix frame model to account the language model on code-switching in case of Bahasa IndonesiaChinese, and Minimalist program of Chomsky (1995) to examine the restrictions on code-switching of both the languages.

The result finds that the language model in the case of Bahasa Indonesia-Chinese code-switching shows that Bahasa Indonesia is the dominant language for most cases. However, the switched with the same structure with Chinese, and have the same frequent occurrence of morpheme cannot be assigned into the ML and EL, only switched cases with system morpheme and Bahasa Indonesia is the frequent morphemes can be accounted into ML or EL. In minimalist program analysis, most cases support the equivalence constraints of Poplack (1981), in which the switched sentence occurs when the surface structure order in the same way. However, the cases of switched sentence between the aspect of time and verb answer the assumption that a switch may occur even the surface structure of the participant languages do not map onto each other. Moreover, the free morpheme constraint analysis using the minimalist program, the bound morphemes of Bahasa Indonesia that denote determiner and possessive, can be cut from its position to project the maximal projection in VP, and still, retain free morpheme. This finding does not violate the free morpheme constraint. However, the passive form switched shows that a switch occurs between bound morpheme and the lexical even the morpheme cannot be cut and retain a free morpheme. By using an analysis of the minimalist program, the result is when the bound morpheme cut from its position to retain a free morpheme, it falls under the lower constituent under PP. Thus, it violates the meaning of the sentence.

\section{References}

Bentahila, A., \& Davies, E. E. (1995). Patterns of code-switching and patterns of language contact. Lingua, 96, 75-93.

Bokamba, E. (1987). Are there syntactic constraints on code-mixing?. In Variation in Language, K. Denning (ed.) (ed.), pp.35-51. Stanford, Calif.: Stanford University Press.

Chan, B. Hok-Shing. (2008). Code-switching, word order and the lexical/functional category distinction. Lingua, $118,777-809$

Chung, S. (2008). Indonesian clause structure from an Austronesian perspective. Lingua, 118, 1554-1582.

Cole, P., \& Hermon, G. (2008). Malay/Indonesian syntax from an Austronesian perspective: An introduction. Lingua. 118, 1431-1439.

Chomsky, N. 1995. The minimalist program. Cambridge, Mass.: MIT Press.

Dewi, C., \& Ekalaya, Y. (2015). An analysis of outer code switching and code mixing in Indonesia Lawyers Club. Literary Criticism Journal 2, 1-6.

Fathimah, D. N. (2016). Why is there code switching in EFL classroom?: A case study in a vocational school in Cimahi West-Java. Journal of English Education 16, 1-8.

Gumperz, J. J. and Blom, J.P. (1971) Social meaning in Linguistic structures: code switching in Norway. In Gumperz, J.J. (1971) Language in social groups. Stanford: Stanford University Press.

Kemaloglu, E. 2018. Patterns of intrasentential code-switching in Turkish-English bilingual discourse: Testing the Free Morpheme and the Equivalence Constraint. Journal of Social Science, 1 (2), 35-45.

Kurdyumov, V. (2014). A course in theoretical Chinese grammar: Principles and contradictions. Procedia - Social and Behavioral Sciences, 116, 3147 - 3151.

Muysken, P. (2000) Bilingual speech: a typology of code mixing. Cambridge: Cambridge University Press.

Myers-Scotton, C. (1993) Duelling Languages: Grammatical Structure in Code Switching. Oxford: Oxford University Press.

Myers-Scotton, C. (1999). Explaining the role of norms and rationality in code-switching. Journal of Pragmatics, $32,1259-1271$.

Myers-Scotton, C. (2008). Language contact: Why outsider system morphemes resist transfer. Journal of Language Contact, 2.

Myers, J. (2019). Knowing Chinese character grammar. Cognition, 147, 127-132.

Mujiono. (2013). Code switching in English as Foreign Language Instruction Practiced by the English lecturers at 
Universities. International Journal of Linguistics, 5, (2).

Mouton, D.G. (Eds.). (2016). Bilingualism across the lifespan. Washington. D.C.: American Psychological Association.

Pujiastuti, Ani (2007). Code-switching as a multilingual strategy in conversations among Indonesian graduate students in the US. Journal of English Education, 1,(2), 10-36.

Radford, Andrew. (2004). Minimalist Syntax: Exploring the structure of English. Cambridge University Press.

Redouane, Rabia. (2005). Linguistics constraints on code mixing and code mixing of bilingual Morrocan ArabicFrance in Canada. ISB4: Proceedings of the 4th International Symposium on Bilingualism, 5.

Romaine, S. (Eds.). (1989). Bilingualism. Oxford: Basil Blackwell Ltd.

Ptaff, C. W. (1979). Constraint on language mixing: Intra-sentential code-switching and borrowing in SpanishEnglish. Linguistics, 55 (2), 219-318.

Popplack, S. (1981). Sometimes I'll start a sentence in Spanish Y TERMINO EN ESPANOL: Toward a typology of code-switching. Linguistic, 18, (7-8), 581-618.

Pulungan, A. H., Sihombing, L., \& Sagala, R. W. (2014). Code switching in Toba Batak wedding ceremony. Garuda Journal, 11, (1), 18-26

Van Gass, K. 2002. Gramatical constraints on intrasentential code switching: Evidence from English-Afrikaans code switching. Research gate, 17, 58-86.

Van Gelderen, E., \& MacSwan, J. (2008). Interface conditions and code-switching: Pronouns, lexical DPs, and checking theory. Lingua, 118, 765-776.

Wang, L. (2019). Distance and word order between lexical heads and noun dependents in Chinese-English codeswitching. Lingua, 223, 67-85.

Wang, L., \& Liu, H. (2016). Syntactic differences of adverbials and attributes in Chinese-English code-switching. Language sciences, 55, 16-35.

Wang, L., \& Liu, H. (2013). Syntactic variations in Chinese-English code-switching. Lingua, 123, 58-73.

Wei, L., \& Milroy, L. (1995). Conversational code-switching in a Chinese community in Britain" A sequential analysis. Journal of Pragmatics, 23, 281-299.

Wen, Q. (2004). Applied Linguistics: Research methods and thesis writing. Beijing: Foreign Language Teaching and Research Press. 